https://doi.org/10.46813/2021-134-055

\title{
WAKEFIELD EXCITATION BY A RAMPED ELECTRON BUNCH TRAIN IN A PLASMA-DIELECTRIC WAVEGUIDE
}

\author{
K.V. Galaydych, G.V. Sotnikov, I.N. Onishchenko \\ National Science Center “Kharkov Institute of Physics and Technology”, Kharkiv, Ukraine \\ E-mail:kgalaydych@gmail.com
}

A linear theory of wakefield excitation by a ramped electron bunch train in a cylindrical plasma-dielectric waveguide is presented. It is shown that during an excitation process the drive bunches are in the focusing field due to the radial electric field excitation of the plasma wave. The possibility of both obtaining a high transformer ratio and focusing the drive and witness bunches is demonstrated.

PACS: 41.75.Lx, 41.75.Ht, 96.50.Pw, 41.75.Jv

\section{INTRODUCTION}

The dielectric-loaded waveguides and resonators are advanced and attractive structures for a high-gradient accelerating field excitation by relativistic electron bunches. In such a structure a intense drive bunch or a train of the bunches excites a high-amplitude wakefield representing Cherenkov radiation in order to accelerate subsequent witness bunches, which should be injected with properly adjusted time delay after the driver. As well as accelerating gradient one of the figures of merit of the structure is a transformer ratio $T$, which determines the efficiency of energy transfer from the drive bunch to the witness bunch. In the simple case the collinear acceleration schemes $T<2[1-3]$. There are several ways to increase the transformer ratio, namely: (i) using a long driver bunch with a linearly increasing current [4], (ii) using a drive bunch sequence of bunches with increasing charge (ramped bunch train) [5 - 8], (iii) using the structures with spaced channels for drive and witness bunches [9, 10]. In [11] it was demonstrated, that a combination of a dielectric-loaded structure and plasma gives an opportunity for the drive and test bunches to be focused. Acceleration in such a plasmadielectric structure is provided by an eigenmode of the dielectric-loaded structure, and focusing is provided by a plasma wave. In this paper, we present a combination of using a ramped electron bunch train and a plasma filling of a channel for charged particles in order to get a high transformer ratio and focusing on both the drive and witness bunches.

\section{STATEMENT OF THE PROBLEM. ANALITYCAL EXPRESSIONS FOR A BUNCH-EXCITED WAKEFIELD}

An accelerating structure under the present investigation is a cylindrical metallic waveguide, partially filled with dielectric with a channel for the charged particles filled with homogeneous cold plasma. A ramped electron bunch train is injected into the plasma channel in parallel to an axis without an offset and propagates downstream the structure. The main goal of this paper is to determine the effect of the plasma filling on a spatial structure of the wakefield components for the case of its excitation by the ramped bunch train. Fig. 1 demonstrates an overview of the plasma-dielectric structure under study.

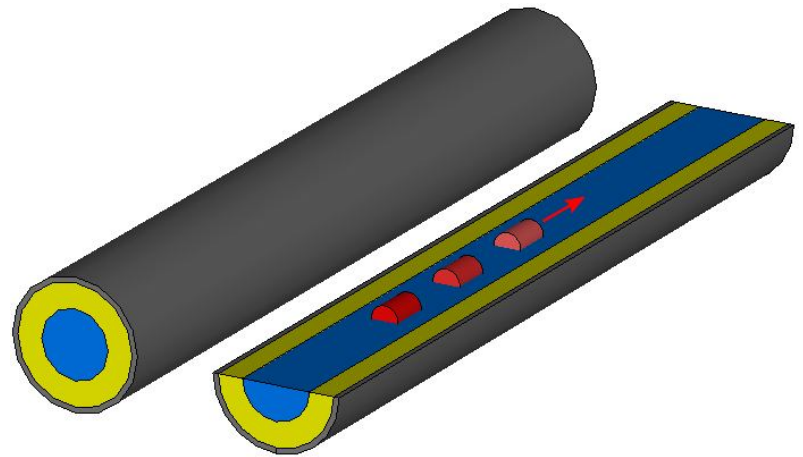

Fig. 1. (Left) General view of a cylindrical plasmadielectric waveguide. The metal coating (grey), dielectric (yellow), plasma (blue) and the electron bunches (red) are shown schematically (Right). A ramped electron bunch train is injected in parallel to the waveguide axis and moves from left to right

In order to get the analytical expressions of wakefield, excited by a drive electron bunch we start with the case of a point particle. We assume that a particle of charge $q$ moves with a constant velocity $v$ along the structure axis ( $z$ direction) and the current density we can write down as follows:

$$
j_{z}=q \frac{\delta\left(r-r_{0}\right)}{r} \delta\left(\varphi-\varphi_{0}\right) \delta\left(t-t_{0}-z / v\right),
$$

where $r_{0}$ and $\varphi_{0}$ are its transverse coordinates, and $t_{0}$ is the particle injection time into the structure $(z=0)$. The electromagnetic field components, and the charge and current densities we expressed in terms of Fourier transformation as follows:

$$
\begin{aligned}
& \mathbf{E}(r, \varphi, \xi)=\sum_{m=-\infty}^{+\infty} e^{i m \varphi} \int_{-\infty}^{+\infty} d \omega \mathbf{E}_{m}^{\omega}(r, \omega) e^{-i \omega \xi}, \\
& \mathbf{D}(r, \varphi, \xi)=\sum_{m=-\infty}^{+\infty} e^{i m \varphi} \int_{-\infty}^{+\infty} d \omega \varepsilon(\omega) \mathbf{E}_{m}^{\omega}(r, \omega) e^{-i \omega \xi}, \\
& \mathbf{H}(r, \varphi, \xi)=\sum_{m=-\infty}^{+\infty} e^{i m \varphi} \int_{-\infty}^{+\infty} d \omega \mathbf{H}_{m}^{\omega}(r, \omega) e^{-i \omega \xi}, \\
& j_{z}(r, \varphi, \xi)=\sum_{m=-\infty}^{+\infty} e^{i m \varphi} \int_{-\infty}^{+\infty} d \omega j_{z m}^{\omega}(r, \omega) e^{-i \omega \xi},
\end{aligned}
$$

where $\xi=t-z / v$. From Maxwell's equations it is possible to derive the wave equations for the Fourier transforms of the axial electric and magnetic fields: 


$$
\begin{aligned}
& \frac{1}{r} \frac{\partial}{\partial r}\left(r \frac{\partial E_{z m}^{\omega}}{\partial r}\right)-\frac{m^{2}}{r^{2}} E_{z m}^{\omega}-\kappa^{2} E_{z m}^{\omega}=\frac{4 \pi i \kappa^{2} j_{z m}^{\omega}}{\omega \varepsilon(\omega)}, \\
& \frac{1}{r} \frac{\partial}{\partial r}\left(r \frac{\partial H_{z m}^{\omega}}{\partial r}\right)-\frac{m^{2}}{r^{2}} H_{z m}^{\omega}-\kappa^{2} H_{z m}^{\omega}=0,
\end{aligned}
$$

where $\kappa^{2}(\omega)=(\omega / v)^{2}\left(1-\beta^{2} \varepsilon(\omega)\right)$ and $\beta=v / c$. The others Fourier transforms of the electric field $E_{r m}^{\omega}, E_{\varphi m}^{\omega}$ and magnetic field $H_{r m}^{\omega}, H_{\varphi m}^{\omega}$ can be expressed in terms of the axial components $E_{z m}^{\omega}$ and $H_{z m}^{\omega}$. For the radial electric field and azimuthal magnetic field the expressions has the following form:

$$
\begin{aligned}
& E_{r m}^{\omega}=\frac{\omega}{c \kappa^{2}}\left(\frac{m}{r} H_{z m}^{\omega}-\frac{i}{\beta} \frac{\partial E_{z m}^{\omega}}{\partial r}\right), \\
& H_{\varphi m}^{\omega}=\frac{\omega}{v \kappa^{2}}\left(\frac{m}{r} H_{z m}^{\omega}-i \beta \varepsilon(\omega) \frac{\partial E_{z m}^{\omega}}{\partial r}\right) .
\end{aligned}
$$

As there are no the offset of the drive bunch we are interested in azimuthally homogeneous field components only $(m=0)$. Taking the inverse Fourier transform, for the wakefield components (Green functions) in the plasma channel we will obtain for the axial force:

$$
\begin{aligned}
& \frac{F_{z}\left(r<r_{0}, \xi, r_{0}, \varphi_{0}, t_{0}\right)}{q}=-2 q k_{p}^{2} \frac{I_{0}\left(k_{p} r\right)}{I_{0}\left(k_{p} a\right)} \Delta_{0}\left(k_{p} a, k_{p} r_{0}\right) \times \\
& \cos \omega_{p}\left(\xi-t_{0}\right) \theta\left(\xi-t_{0}\right)-\sum_{s=1} \frac{4 q}{a \omega_{s} D^{\prime}\left(\omega_{s}\right)} \frac{I_{0}\left(\kappa_{p s} r\right) I_{0}\left(\kappa_{p s} r_{0}\right)}{I_{0}^{2}\left(\kappa_{p s} a\right)} \times \\
& \cos \omega_{p}\left(\xi-t_{0}\right) \theta\left(\xi-t_{0}\right), \\
& \frac{F_{z}\left(r_{0}<r<a, \xi, r_{0}, \varphi_{0}, t_{0}\right)}{q}=-2 q k_{p}^{2} \frac{I_{0}\left(k_{p} r_{0}\right)}{I_{0}\left(k_{p} a\right)} \Delta_{0}\left(k_{p} a, k_{p} r\right) \times \\
& \cos \omega_{p}\left(\xi-t_{0}\right) \theta\left(\xi-t_{0}\right)-\sum_{s=1} \frac{4 q}{a \omega_{s} D^{\prime}\left(\omega_{s}\right)} \frac{I_{0}\left(\kappa_{p s} r\right) I_{0}\left(\kappa_{p s} r_{0}\right)}{I_{0}^{2}\left(\kappa_{p s} a\right)} \times \\
& \cos \omega_{p}\left(\xi-t_{0}\right) \theta\left(\xi-t_{0}\right),
\end{aligned}
$$

and for the radial force:

$$
\frac{F_{r}\left(r<r_{0}, \xi, r_{0}, \varphi_{0}, t_{0}\right)}{q}=2 q k_{p}^{2} \frac{I_{1}\left(k_{p} r\right)}{I_{0}\left(k_{p} a\right)} \Delta_{0}\left(k_{p} a, k_{p} r_{0}\right) \times
$$

$\sin \omega_{p}\left(\xi-t_{0}\right) \theta\left(\xi-t_{0}\right)+\sum_{s=1} \frac{4 q v \kappa_{p s}}{a \omega_{s}^{2} D^{\prime}\left(\omega_{s}\right)} \frac{I_{1}\left(\kappa_{p s} r\right) I_{0}\left(\kappa_{p s} r_{0}\right)}{I_{0}^{2}\left(\kappa_{p s} a\right)} \times$ $\sin \omega_{p}\left(\xi-t_{0}\right) \theta\left(\xi-t_{0}\right)$,

$$
\frac{F_{r}\left(r_{0}<r<a, \xi, r_{0}, \varphi_{0}, t_{0}\right)}{q}=-2 q k_{p}^{2} \frac{I_{0}\left(k_{p} r_{0}\right)}{I_{0}\left(k_{p} a\right)} \Delta_{1}\left(k_{p} r, k_{p} a\right) \times
$$$$
\sin \omega_{p}\left(\xi-t_{0}\right) \theta\left(\xi-t_{0}\right)+\sum_{s=1} \frac{4 q v \kappa_{p s}}{a \omega_{s}^{2} D^{\prime}\left(\omega_{s}\right)} \frac{I_{1}\left(\kappa_{p s} r\right) I_{0}\left(\kappa_{p s} r_{0}\right)}{I_{0}^{2}\left(\kappa_{p s} a\right)} \times
$$$$
\sin \omega_{p}\left(\xi-t_{0}\right) \theta\left(\xi-t_{0}\right)
$$

where $\omega_{p}$ is a plasma frequency; $k_{p}=\omega_{p} / v$ is a plasma wavenumber; $a$ is an inner radius of the dielectric; $\Delta_{n}(x, y)=I_{n}(x) K_{0}(y)-(-1)^{n} K_{n}(x) I_{0}(y), I_{n}$ and $K_{n}$ are the modified Bessel and Macdonald functions of the $\mathrm{n}^{\text {th }}$ order; $\kappa_{p s}=\kappa_{p}\left(\omega_{s}\right), \quad \varepsilon_{p}(\omega)=1-\omega_{p}^{2} / \omega^{2}$ is the plasma permittivity, $D^{\prime}\left(\omega_{s}\right)=d D\left(\omega_{s}\right) / d \omega ; \theta$ is the Heaviside function. The frequencies the eigen modes for the plasma-dielectric waveguide $\omega_{s}$ are determined by a dispersion equation

$$
\frac{\varepsilon_{p}}{\kappa_{p}} \frac{I_{1}\left(\kappa_{p} a\right)}{I_{0}\left(\kappa_{p} a\right)}+\frac{\varepsilon_{d}}{\kappa_{d}} \frac{F_{1}\left(\kappa_{d} a, \kappa_{d} b\right)}{F_{0}\left(\kappa_{d} a, \kappa_{d} b\right)}=0,
$$

where $\kappa_{p}^{2}=(\omega / v)^{2}\left(1-\beta^{2} \varepsilon(\omega)\right), \varepsilon_{d}$ is a permittivity of the dielectric, $\kappa_{d}^{2}=(\omega / v)^{2}\left(\beta^{2} \varepsilon_{d}-1\right) ; b$ is an outer dielectric radius, $F_{0}(x, y)=J_{0}(x) Y_{0}(y)-Y_{0}(x) J_{0}(y)$, $F_{1}(x, y)=-J_{1}(x) Y_{0}(y)+Y_{1}(x) J_{0}(y)$, and $J_{n}$ and $Y_{n}$ are the $\mathrm{n}^{\text {th }}$ order Bessel and Webber functions respectively.

The field components expressions of a finite-size drive bunch can be get, based on the point particle solution by the integration over the injection time $t_{0}$ and transverse position $r_{0}$. We suppose that each drive bunch in the ramped bunch train has a square profile of the charge density in both longitudinal and transverse directions (uniform distribution). The charge of each bunch in the train grows as an odd number. As a result the final expression for the axial force, acting on the bunches, is

$$
\begin{aligned}
& \frac{F_{z}\left(r \leq R_{b}, \xi\right)}{q}=-\frac{4 Q_{b}}{R_{b} L_{b}} \sum_{i=1}^{N_{b}} \frac{2 i-1}{2 N_{b}-1}\left(\frac{1}{k_{p} R_{b}}-\frac{I_{0}\left(k_{p} r\right)}{I_{0}\left(k_{p} a\right)} \times\right. \\
& \left.\Delta_{1}\left(k_{p} R_{b}, k_{p} a\right)\right) \Psi_{\|}^{(p)}(\xi)-\frac{8 Q_{b}}{R_{b} L_{b}} \sum_{i=1}^{N_{b}} \sum_{s=1} \frac{(2 i-1)}{\left(2 N_{b}-1\right)} \times \\
& \frac{v}{a \kappa_{p s} \omega_{s}^{2} D^{\prime}\left(\omega_{s}\right)} \frac{I_{0}\left(\kappa_{p s} r\right) I_{0}\left(\kappa_{p s} R_{b}\right)}{I_{0}^{2}\left(\kappa_{p s} a\right)} \Psi_{\|}^{(s)}(\xi),
\end{aligned}
$$

and for the radial force

$$
\begin{aligned}
& \frac{F_{r}\left(r \leq R_{b}, \xi\right)}{q}=-\frac{4 Q_{b}}{R_{b} L_{b}} \sum_{i=1}^{N_{b}} \frac{2 i-1}{2 N_{b}-1} \frac{I_{1}\left(k_{p} r\right)}{I_{0}\left(k_{p} a\right)} \times \\
& \Delta_{1}\left(k_{p} R_{b}, k_{p} a\right) \Psi_{\perp}^{(p)}(\xi)+\frac{8 Q_{b}}{R_{b} L_{b}} \sum_{i=1}^{N_{b}} \sum_{s=1} \frac{(2 i-1)}{\left(2 N_{b}-1\right)} \times \\
& \frac{v^{2}}{a \omega_{s}^{3} D^{\prime}\left(\omega_{s}\right)} \frac{I_{1}\left(\kappa_{p s} r\right) I_{1}\left(\kappa_{p s} R_{b}\right)}{I_{0}^{2}\left(\kappa_{p s} a\right)} \Psi_{\perp}^{(s)}(\xi),
\end{aligned}
$$

where $R_{b}$ is the bunch radius, $L_{b}$ is the bunch length, $N_{b}$ is a number of the drive bunches in the train and $Q_{b}$ is the charge of the last bunch in their sequence.

The functions $\Psi_{\|}^{(p, s)}(\xi)$ and $\Psi_{\perp}^{(p, s)}(\xi)$ describe the axial structure of the bunch-excited wakefield components.

$$
\begin{aligned}
& \Psi_{\|}^{(p, s)}=\theta\left(\xi-(i-1) T_{r}\right) \sin \omega_{p, s}\left(\xi-(i-1) T_{r}\right)- \\
& \theta\left(\xi-(i-1) T_{r}-T_{b}\right) \sin \omega_{p, s}\left(\xi-(i-1) T_{r}-T_{b}\right), \\
& \Psi_{\perp}^{(p, s)}=\theta\left(\xi-(i-1) T_{r}\right)\left(1-\cos \omega_{p, s}\left(\xi-(i-1) T_{r}\right)\right)- \\
& \theta\left(\xi-(i-1) T_{r}-T_{b}\right)\left(1-\cos \omega_{p, s}\left(\xi-(i-1) T_{r}-T_{b}\right)\right),
\end{aligned}
$$

where $T_{r}$ is a bunch repetition time, $T_{b}=L_{b} / v$ is a bunch duration.

\section{NUMERICAL ANALYSIS RESULTS}

The derived expressions of the bunch-excited wakefield components allow to carry out the numerical analysis of an excitation process and a spatial structure 
of the electromagnetic field in the plasma-dielectric accelerating structure in a rigid drive bunches approximation. For the numerical analysis in the gigahertz frequency range we used the parameters of the waveguide and the train of electron bunches accessible at Kharkov Institute of Physics and Technology (linac "Almaz2M"): energy of electron bunch is $4.5 \mathrm{MeV}$, a repetition bunch spacing $L_{\text {mod }}=10.64 \mathrm{~cm}$, the outer radius of the dielectric (it was fixed) $b=4.25 \mathrm{~cm}$, the permittivity of the dielectric material $\varepsilon_{d}=2.045$ (the teflon), the plasma density is $10^{10} \mathrm{~cm}^{-3}$ We suppose that the repetition bunch length equals to a sum of the first radial mode wavelength $\lambda_{1}$ and the drive bunch length, i.e. $L_{\text {mod }}=\lambda_{1}+L_{b}$. The inner dielectric radius changed in our numerical calculations depending on a frequency of a working mode and the length of the drive bunch. It should be noted, that the dielectric material supposed to be dispersion free.

The main goal of the numerical investigations in present paper was to analyze the possibility of obtaining a high value of the transformer ratio and simultaneous radial focusing of both drive and witness electron bunches in the process of wakefield excitation and acceleration respectively. Fig. 2 demonstrates the longitudinal distributions of an axial force $F_{z} / q=E_{z}$ and a radial force $F_{r} / q=E_{r}-\beta H_{\varphi}$, acting as on the drive bunches as a trailing test bunch for the case $\lambda_{1}=8.84 \mathrm{~cm}$, $L_{b}=1.79 \mathrm{~cm}, a=2.19 \mathrm{~cm}$ and $R_{b}=1.5 \mathrm{~cm}$.

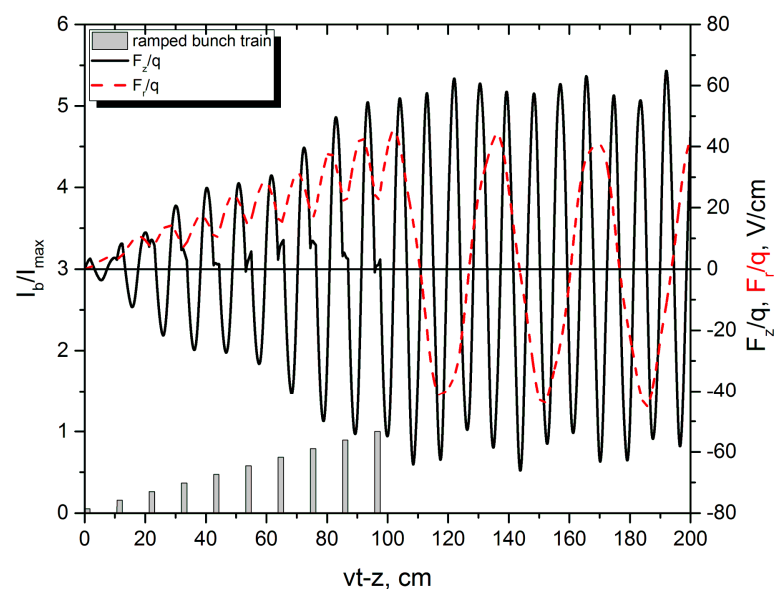

Fig. 2. The axial profiles of the longitudinal (solid line) and radial (dashed line) forces excited by the bunches,

at the distance $r=R_{b}$ from the waveguide axis.

The ramped bunch train (the grey rectangles) move from right to left, a position of the first bunch in the train corresponds to $v t-z=0$

It can be seen that there is a significant qualitative difference between the axial profiles. The main reason is as follows. Excitation of the longitudinal electric field is provided by the field of eigenmodes of the plasmadielectric waveguide. And radial force excitation is provided by the field of plasma wave. The presented field distributions shows, that for the chosen set of parameters: (i) a decelerating electric field oscillate along the drive bunch train, which leads to nonuniform drive bunches energy loss, (ii) all the drive bunches are in growing focusing fields with oscillating amplitude along the drive bunch train as well, which is a positive feature of the plasma-dielectric structure, that, in turn, leads to to improve transverse drive bunches stability and could provide higher length of accelerating structure to be planned, (iii) due to the difference in the wavelengths of the working eigenmode of the structure $(8.84 \mathrm{~cm})$ and the plasma wavelength $(33.22 \mathrm{~cm})$ provides a possibility to determine the locations (or time of injection) for the test electron or positron bunches to be accelerated and focused simultaneously. A transformer ratio, which calculated as ratio of a maximal accelerating electric field amplitude behind the last drive bunch to a maximal decelerating electric field amplitude equals $T \sim 7$. In order to provide a uniform deceleration of all drive bunches in the ramped bunch train and even their energy loss it is necessary to choose the length of each drive bunch to be equal to the half of the operating mode wavelength $L_{b}=\lambda_{1} / 2$. In this case the waveguide parameters equal as follows: inner dielectric radius $a=2.93 \mathrm{~cm}$ and the operating mode wavelength $\lambda_{1}=7.09 \mathrm{~cm}$. Fig. 3 shows the axial distributions of $F_{z} / q$ and $F_{r} / q$, which are corresponding to aforementioned case.

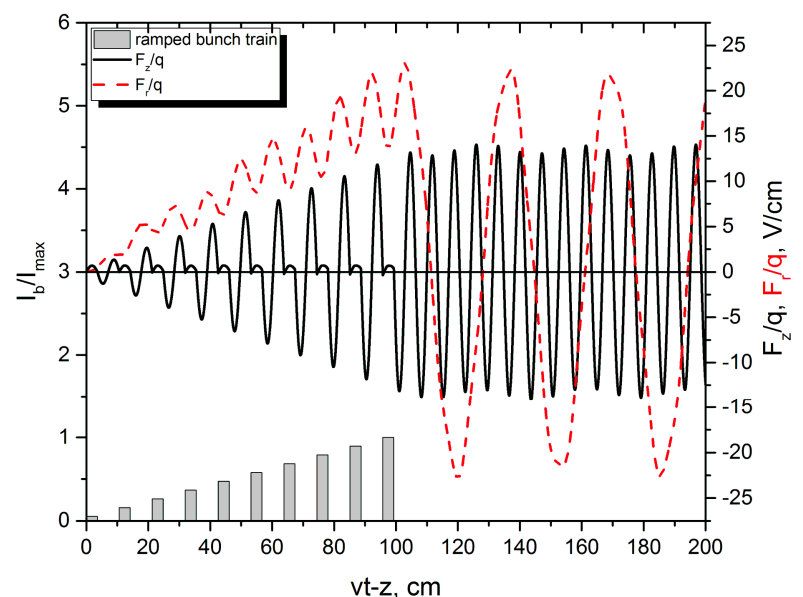

Fig. 3. The axial profiles of the longitudinal (solid line) and radial (dashed line) forces excited in the waveguide at the distance $r=R_{b}$ from the axis, which are corre-

sponding to the case of the uniform deceleration of all drive bunches. The ramped bunch train (the grey rectangles) move from right to left, a position of the first bunch in the train corresponds to $v t-z=0$

Fig. 3 demonstrates that in this case (in comparison with previous case) the decelerating electric field does not oscillate along the bunch sequence, which leads to even drive bunches energy loss. A necessary adjustment of the parameters also leads to: (i) an increase in the transformation ratio $T \sim 20$, (ii) a change in the ratio between the amplitudes of the longitudinal and transverse forces. At the same time a possibility of test electron bunches acceleration with their simultaneous focusing in the wakefield field, excited by drive bunches, remains. The focusing fields amplitude increase leads, in turn, to weaker requirements for external focusing systems (in the case of their use) in order to suppress the transverse instabilities, that can take place during the passage of bunches through the accelerating structure. So far, we have considered the parameters of the waveguide and electron bunches, which are as close as possi- 
ble to the planned experiments in terms of the repetition bunch length. In the paper [12] it was shown that at certain plasma density it is possible to achieve the total axial electric field increase by a coherent summation of the eigenwaves field and the plasma wave field. This case corresponds to the set of parameters as follows: $a=1.09 \mathrm{~cm}, \quad b=4.31 \mathrm{~cm}, \varepsilon=2.1, n_{p}=10^{11} \mathrm{~cm}^{-3}$, $\lambda_{1}=10.6 \mathrm{~cm}, L_{b}=5.3 \mathrm{~cm}, R_{b}=0.3 \mathrm{~cm}$.

Fig. 4 shows that in this case the axial distribution of the longitudinal force remains similar to the two cases presented before, but the profile of the transverse force change qualitatively due to the fact, that the wavelength of the working eigenmode almost coincides with the length of the plasma wave.

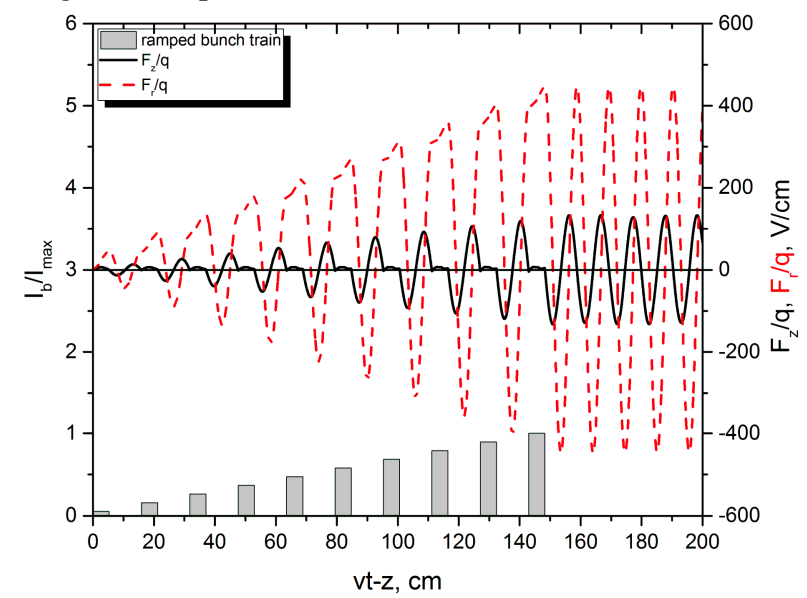

Fig. 4. The axial profiles of the longitudinal (solid line) and radial (dashed line) forces excited in the waveguide at the distance $r=R_{b}$ from the axis, which are corresponding to the case of a coherent summation of the working eigenmode field and plasma wave field.

The ramped bunch train (the grey rectangles) move from right to left, a position of the first bunch in the train corresponds to $v t-z=0$

Numerical analysis shows, that the axial field amplitude of the plasma wave becomes comparable to the axial field amplitude of the working eigenmode of the structure. In this case the transformer ratio $T \sim 20.6$. The amplitude of the transverse field increases due to coherent summation from the bunches of the sequence and the drive bunches remain of the focusing phases of the field. But despite an even more significant increase in the focusing field behind the drive bunches, the phase area for the test bunches becomes more narrow. The possible positions for test electron bunches, which provide their acceleration with simultaneous focusing are still remain, but they are placed on the field slope and this fact will lead to a linear energy spread. To minimize this negative effect, short test bunches should be used.

\section{CONCLUSIONS}

The analytical and numerical studies of the wakefield excitation in a cylindrical plasma-dielectric waveguide by a ramped profiled regular sequence of electron drive bunches has been carried out. The constructed expressions of the bunch-excited electromagnetic field components can be used in order to get more detailed interpretation of the experimental results. The possibility of the transformer ratio increase, and also focusing both drive and witness bunches for the collinear accelerating structures of gigahertz frequency range for the planned experiments has been demonstrated.

\section{ACKNOWLEDGEMENTS}

The study is supported by NAS of Ukraine Program "Plasma physics and plasma electronics: basic researches and applications", Project P-2/63-2021.

\section{REFERENCES}

1. R.D. Ruth, A.W. Chao, P.L. Morton, and P.B. Wilson. A plasma wake field accelerator // Particle Accelerators. 1985, v. 17, № 3-4, p. 171-189.

2. G.A. Voss and T. Weiland. Particle acceleration by wakefields // Report No. DESY M-82-10, 1982.

3. K.L.F. Bane, P.B. Wilson, and T. Weiland. Wake fields and wake field acceleration, in Physics of High Energy Particle Accelerator // AIP Conf. Proc. 1985, № 127, p. 875-928.

4. K.L.F. Bane, P. Chen, P.B. Wilson. On collinear wake field acceleration // IEEE Trans. Nucl. Sci. 1985 , v. 32, p. 3524-3526.

5. C. Jing, A. Kanareykin, J.G. Power, et al. Observation of Enhanced Transformer Ratio in Collinear Wakefield Acceleration // Phys. Rev. Lett. 2007, v. 98, p. 144801.

6. J.T. Seeman. Collective Electron Driven Linac for High Energy Physics // IEEE Trans. Nucl. Sci. 1983, v. 30, № 4, p. 3180-3182.

7. S.S. Vahanian, E.M. Laziev, V.M. Tsakanov. O koeffitsiyente transformatsii $\mathrm{v}$ cxemax uskoreniya kilvaternym polem // Problems of atomic science and technology. 1990, № 7, p. 32-36.

8. I.L. Sheinman, A.D. Kanareykin. Transverse dynamics and bunch-to-bunch energy exchange in a dielectric-filled accelerating structure // Technical physics. 2008, v. 53, № 10, p. 1350-1356.

9. G.V. Sotnikov, T.C. Marshall, J.L. Hirshfield. Coaxial two-channel high-gradient dielectric wakefield accelerator // Phys. Rev. ST AB. 2009, v. 12, p. 061302 .

10. S.V. Shchelkunov, T.C. Marshall, G. Sotnikov, et al. Comparison of experimental tests and theory for a rectangular two-channel dielectric wakefield accelerator structure // Phys. Rev. ST AB. 2012, v. 15, p. 031301.

11. G.V. Sotnikov, R.R. Kniaziev, O.V. Manuilenko, et al. Analytical and numerical studies of underdense and overdense regimes in plasma-dielectric wakefield accelerators // Nucl. Instrum. Meth. A. 2014, v. 740, p. 124-129.

12. R.R. Knyazev, I.N. Onishchenko, G.V. Sotnikov. Generation of wakefields in a dielectric structure filled with plasma // Technical physics. 2016, v. 61, № 4, p. 511-516.

Article received 18.06.2021 
ВОЗБУЖДЕНИЕ КИЛЬВАТЕРНОГО ПОЛЯ В ПЛАЗМЕННО-ДИЭЛЕКТРИЧЕСКОМ ВОЛНОВОДЕ ПРОФИЛИРОВАННОЙ ПОСЛЕДОВАТЕЛЬНОСТЬЮ ЭЛЕКТРОННЫХ СГУСТКОВ

\section{К.В. Галайдыч, Г.В. Сотников, И.Н. Онищенко}

Представлена линейная теория возбуждения кильватерного поля профилированной последовательностью электронных сгустков в цилиндрическом плазменно-диэлектрическом волноводе. Показано, что в процессе возбуждения драйверные сгустки находятся в фокусирующем поле за счет возбуждения радиального электрического поля плазменной волны. Продемонстрирована как возможность получения высокого коэффициента трансформации, так и фокусировки драйверных и ускоряемых сгустков.

\section{ЗБУДЖЕННЯ КІЛЬВАТЕРНОГО ПОЛЯ В ПЛАЗМОВО-ДІЕЛЕКТРИЧНОМУ ХВИЛЕВОДІ ПРОФІЛЬОВАНОЮ ПОСЛІДОВНІСТЮ ЕЛЕКТРОННИХ ЗГУСТКІВ}

\section{К.В. Галайдич, Г.В. Сотніков, І.М. Оніщенко}

Представлено лінійну теорію збудження кільватерного поля профільованою послідовністю електронних згустків у циліндричному плазмово-діелектричному хвилеводі. Показано, що в процесі збудження драйверні згустки знаходяться у фокусуючому полі за рахунок збудження радіального електричного поля плазмової хвилі. Продемонстровано як можливість отримання високого коефіцієнта трансформації, так і фокусування драйверних згустків та згустків що, прискорюються. 